\title{
(PER)FORMAÇÕES DE UM DESENHO INCORPORADO
}

\author{
Virna da Silva Bemvenuto ${ }^{\mathrm{i}}$ \\ Letícia Carvalho da Silva de Oliveira ${ }^{\text {ii }}$
}

Resumo: O presente relato de experiência se faz como um compartilhamento reflexivo das práticas artístico-pedagógicas realizadas no projeto O Corpo nas Artes Visuais, no Colégio de Aplicação da UFRJ. A partir de proposições onde o corpo é requisitado para a produção de imagem, investiga-se os tensionamentos oriundos do processo de desnaturalização das posturas corporais pré-estabelecidas para o ato de desenhar e também para as aulas de Artes Visuais em espaços formais de ensino. Desse modo, procura-se compreender o corpo como matéria sensível, caminho para o gesto no desenho e como lugar privilegiado de experimentação.

Palavras-chave: Experiência; Corpo; Movimento; Arte; Educação.

\section{(PER)FORMATIONS OF AN INCORPORATED DRAWING}

\begin{abstract}
This experience report is a reflexive sharing of the artistic-pedagogical practices performed in the project The Body in the Visual Arts, at the UFRJ Colégio de Aplicação. From propositions where the body is required for image production, we investigate the tensions arising from the denaturalization process of pre-established body postures for the act of drawing and also for Visual Arts classes in formal teaching spaces. Thus, we seek to understand the body as a sensitive matter, a path for gesture in drawing and as a privileged place for experimentation.
\end{abstract}

Keywords: Experience; Body; Movement; Art; Education.

O corpo existe e pode ser pego.

É suficientemente opaco para que se possa vê-lo. Se ficar olhando anos você pode ver crescer o cabelo.

O corpo existe porque foi feito.

Por isso tem um buraco no meio. O corpo existe, dado que exala cheiro.

E em cada extremidade existe um dedo.

O corpo se cortado espirra um líquido vermelho.

O corpo tem alguém como recheio.

Arnaldo Antunes

Entrar na sala e avistar um enorme papel em branco. Ser convidado a estar sobre ele. O corpo: um ponto sobre o branco. Ponto de partida, lugar de onde avistamos o mundo. Descobrir 
que existe um papel tão grande que cabe o corpo inteiro e, portanto, cabe o inteiriço desejo de se dizer também como mundo. Com um giz na mão o desenho acontece. O gesto impregna a superfície, se desloca, o desenho se compõe como registro dos movimentos do desejo: desejo de se dizer feito matéria.

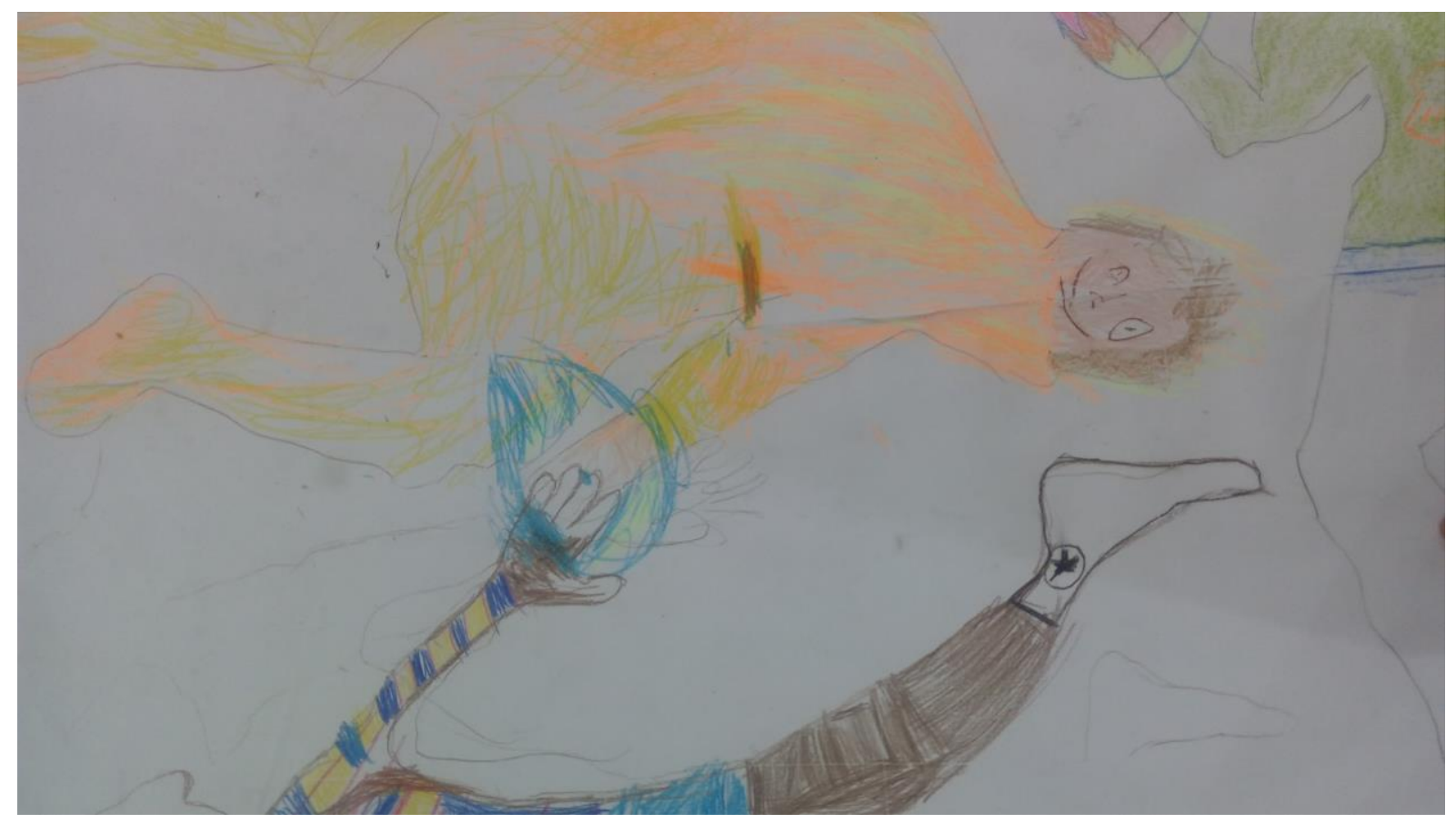

Imagem 1 - Registro de aula. Cap-UFRJ, 2019.

As crianças foram convidadas a realizarem desenhos com corpo deitado sobre um grande papel em branco. No espaço compartilhado, encosta aqui, encosta acolá, cada um foi encontrando sua maneira de se acomodar. Com um giz de cera na mão, foi proposto que traçassem o contorno do próprio corpo. Isso implicava micro-deslocamentos: para contornar uma parte é preciso mover outra. Nesse momento, emergiu o primeiro conflito. Uma das crianças dizia eu não consigo, eu não consigo!. E outra dizia ao olhar seu contorno já traçado: essa não é a forma do meu corpo!. Nesse processo, um corpo encostava no outro. O encontro dos corpos pelo contato foi o segundo ponto de conflito: a noção de fronteira. Conforme os corpos se tocavam pela pele, limiar entre o eu e o mundo, algumas crianças consideravam seus espaços demarcados pelos contornos violados pela presença do outro. Entre incômodos e encaixes, como co-habitar? Nessa negociação, brigar pelo território ou desterritorializar?

Após contornarem seus corpos, foi solicitado que caminhassem sobre o papel e tentassem ocupar o contorno de um outro corpo, o de um colega: tem como caber no contorno 
do outro?. Convidando as crianças a outros modos de estar em um contorno que não é o seu surgiu a seguinte resposta: a posição confortável para ele não é para mim.

Ao olharem seus desenhos na roda de compartilhamento da experiência, os gestos tornados palavras:

José: "estranho", "os encontros deixaram marcas no meu corpo"

Miguel: "eu entrei no corpo do Gabriel e achei estranho"

Luís: "dor, porque eu abro muito a perna quando faço isso aqui"

Laura: "cansada, descansada, linda, maravilhosa"

Gabriel: "o meu corpo é esse que está com a roupa da Calvin Klein”, “eu sinto na aula de artes o meu rosto meio arranhado, um negócio que começa pequeno e depois vai crescendo"

Bento: "eu sinto espiritualmente"

Lavínia: "essa é minha boneca. Não! Esse é o meu corpo"

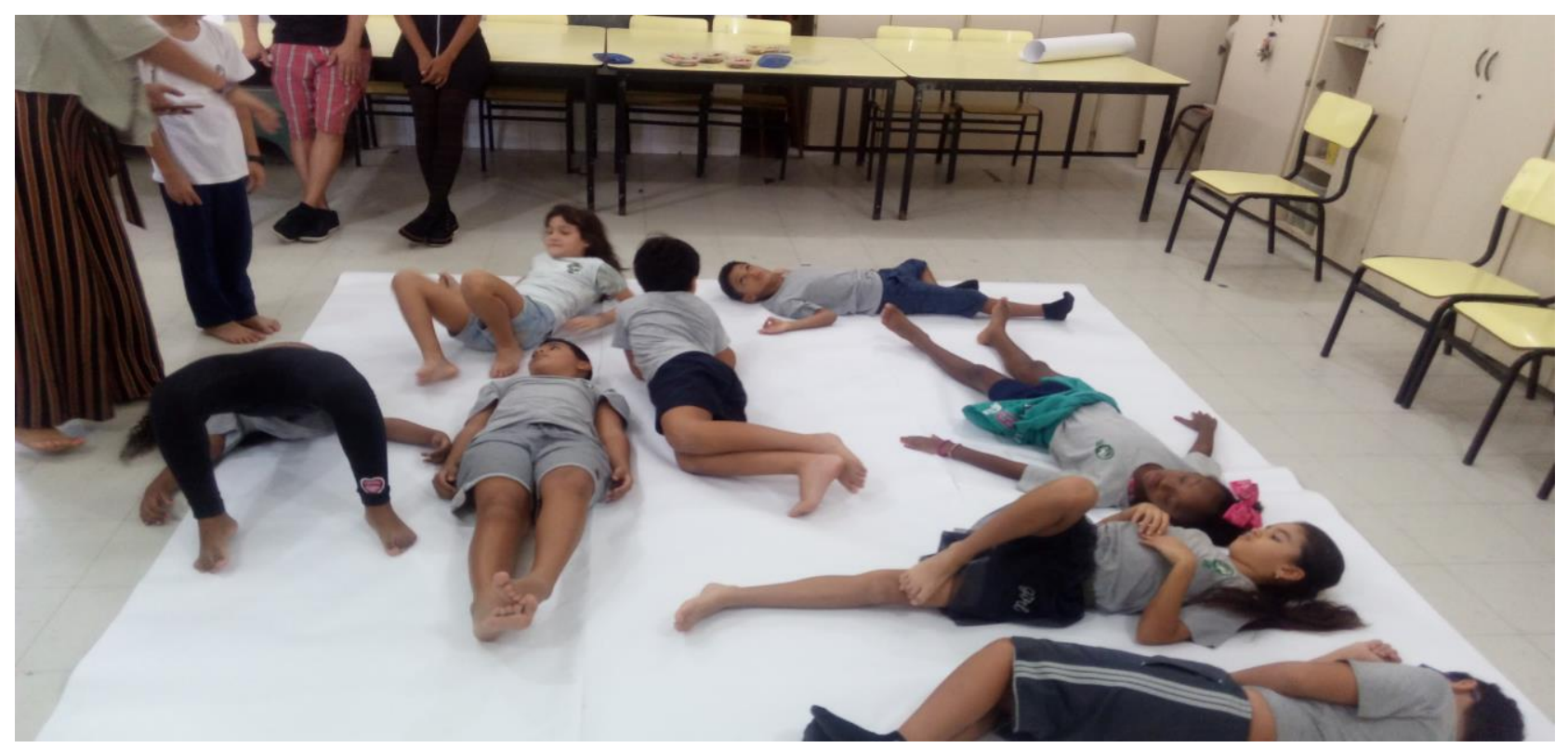

Imagem 2 - Registro de aula. Cap-UFRJ, 2019.

\section{Mergulho}

Entre percursos e percalços, miramos um horizonte: a linha, lá na frente, evidência do limiar entre o céu e a terra, terra onde com os pés bem plantados no chão, percorremos a longa estrada da prática docente. Com as muitas pedras encontradas no meio do caminho, alguns meios caminhos, com a sede e a coragem de acreditar que o copo está sempre meio cheio e não 
meio vazio. Nos saltam os seguinte questionamentos: O que pode o corpo no ambiente escolar? O que pode a relação estabelecida entre corpo adulto - professora - e o corpo da criança estudante -, ambos em formação no ambiente escolar?

A escola, elaborada historicamente como dispositivo disciplinar e de controle, cumpre o papel da formação. Preocupada em dar forma - forma ansiada socioculturalmente - a instituição escolar investe em práticas que reforçam a dicotomia corpo x mente, largamente experimentadas na formação do pensamento ocidental. Dicotomia essa instaurada pelos processos de colonização européia, cujo pensamento privilegia razão-de-ser-não-sei-o quê, garante, até hoje, uma hegemonia epistemológica diante da qual desaprendemos a conviver com o corpo e suas complexidades.

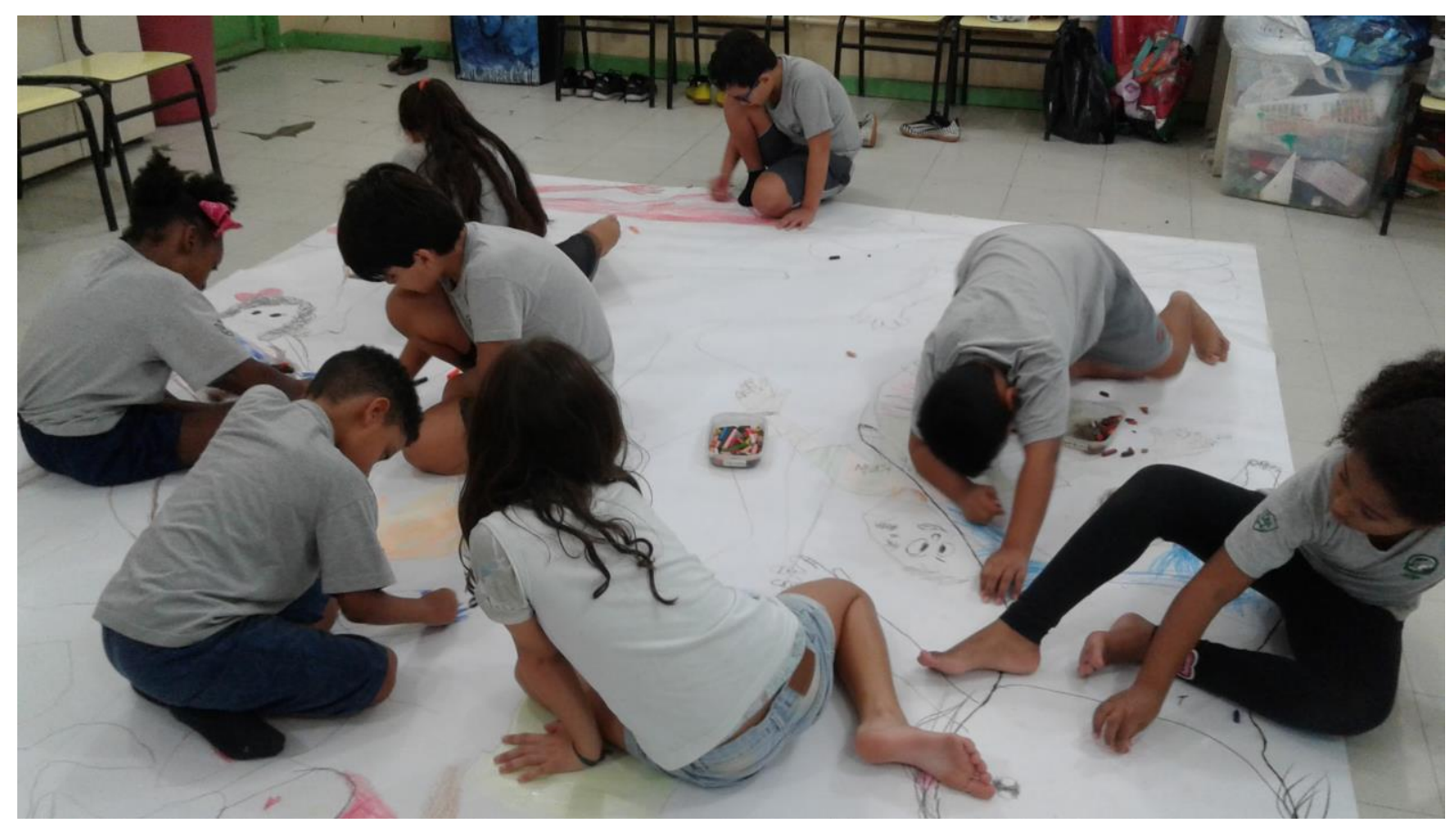

Imagem 3 - Registro de aula. Cap-UFRJ, 2019.

Negar o corpo, no contexto da escola moderna, é corroborar com os processos colonizadores que fundamentam a cultura de dominação. Propomos então a convocação do corpo considerando que quando começamos a falar em sala de aula sobre o corpo, sobre como vivemos no corpo, estamos automaticamente desafiando o modo como o poder se orquestrou nesse espaço institucionalizado em particular (HOOKS, 2019, p. 183).

Diante dessa tradicional orquestração do poder, caminhamos ao encontro da presença do corpo na escola como aposta na desconstrução de um modelo de educação que opera por séculos facultando subjetividade a alguns grupos específicos e negando-a a outros (HOOKS, 
2019). Bell Hooks (2019, p. 186) destaca que ao reconhecermos a subjetividade e os limites da identidade, rompemos essa objetificação tão necessária numa cultura de dominação.

Como aponta Terezinha Nóbrega (2008), durante o processo de formação desaprendemos a conviver com a realidade corpórea, com a experiência dos sentidos, pois privilegiamos uma razão sem corpo. No entanto, a percepção, compreendida como um acontecimento da existência, pode resgatar este saber corpóreo (NÓBREGA, 2008, p.142). Assim, confrontadas por nossos interesses de pesquisa em incorporar os processos de criação, atuando no projeto $O$ Corpo nas Artes Visuais no CAp-UFRJ, propomos para as turmas de $3^{\circ}$ ano do Ensino Fundamental $1^{\circ}$ segmento uma série de práticas que requisitam o corpo na produção das visualidades no âmbito da imagem e da performatividade dos corpos.

Buscamos em Terezinha Nóbrega (2008), que nos conta acerca da fenomenologia de Maurice Merleau-Ponty, uma interlocução com as nossas reflexões acerca das práticas corporais e expressivas realizadas com as turmas 13A e 13B no CAp-UFRJ. Partimos da sensação para traçarmos um caminho até a produção da imagem em desenho. A sensação como disparadora do gesto confere um desenho em campo ampliado - termo transposto do conceito "escultura em campo ampliado" ensaiado por Rosalind Krauss e publicado no número 8 da revista October (1979), a respeito do alargamento da linguagem escultórica tradicional que passa a se desdobrar em outras formas de relação com o espaço no contexto da pós-modernidade - um desenho de corpo inteiro, que não se restringe a uma pequena folha ou a uma atividade mental.

Trata-se de um desenho que atravessa o corpo e desemboca no espaço do papel. Um desenho que existe em em forma de desejo, que antes de ser visto pode ser sentido e que é manifestado na superfície como rastro, marca, memória, testemunha de uma experiência do corpo, mas não só isso: ele assume seu lugar de linguagem pelos modos de uso da linha, das formas, da cor, das proporções, da composição articuladas às dinâmicas corporais. Ou seja, um desenho corporificado e não um desenho que se dá apenas como educação do olhar ou como processo mental. É também um processo relacional do indivíduo com o próprio corpo enquanto realidade matérica e expressiva que o convoca à presença e que se exprime com seus pesos, forças, ritmos e intensidades que se revelam no traço. Um modo de desenhar que nos ensina a olhar com o corpo inteiro. A partir dessas vivências, motivadas pelas experiências nas relações corpo-arte-escola, compartilhamos um pouco das ações poéticas de tais proposições. 


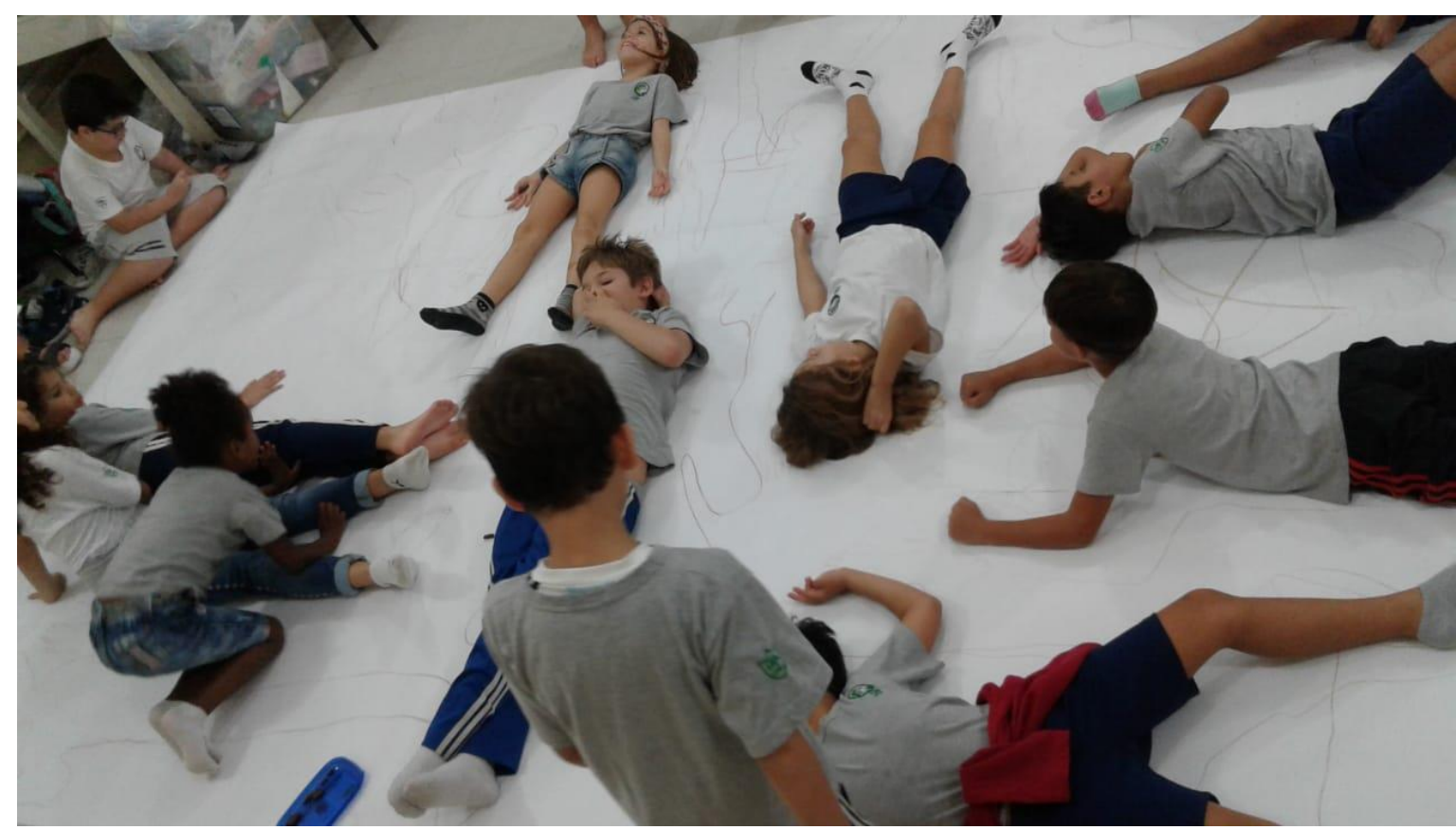

Imagem 4 - Registro de aula. Cap-UFRJ, 2019.

O gesto como palavra primordial, que antecede a fala, corporifica o dizer. A palavra tornada gesto é dita com o corpo, desemboca nele. Quando anunciado no traço, o gesto pode ser visto, sua memória revista:

Sendo a primeira palavra gesto, afirma-se um novo sentido para o logos, realiza-se, desse modo, a leitura da dimensão poética e plástica do corpo em movimento e da percepção. Trata-se de uma nova possibilidade de leitura do real e da linguagem sensível, procedendose pela reversibilidade dos sentidos (NÓBREGA, 2008. p. 143).

Tal reversibilidade dos sentidos aponta um caminho para a percepção onde se pode ver com as mãos, apalpar com os olhos, enxergar com a pele pela comunicabilidade dos sentidos. O corpo, então, passa a ser reconhecido como complexidade sensível e não como um arranjo de órgãos.

Diante das práticas propostas para a turma 13B ao longo do $2^{\circ}$ trimestre de 2019 , onde o elemento disparador era o corpo em movimento, as aulas de artes visuais foram provocadoras do cultivo da coragem: como (ar)riscar a folha em branco? Fazer nascer um mundo com um giz na mão? Desenhar nasce dessa vontade, da noção de que há zonas da existência que não se oferecem à nossa compreensão sem um esforço que vença a inércia e que provoque o gesto e a marca. (REGO apud HORTA, 2010. p. 17) 


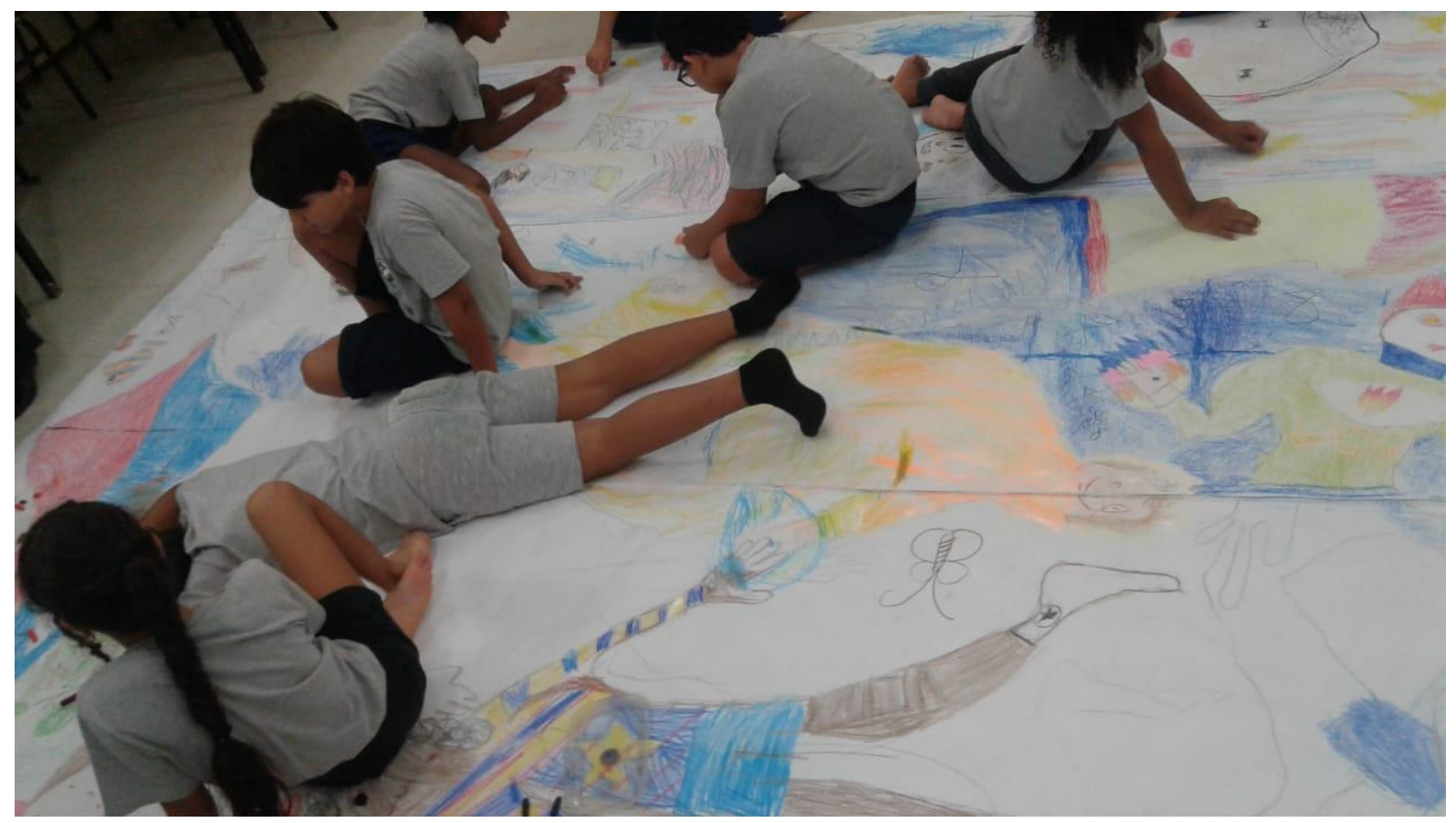

Imagem 5 - Registro de aula. Cap-UFRJ, 2019.

Ao convidarmos os corpos lançando a provocação de desenhar em posturas não convencionais, nos damos conta de uma espécie de travessia enfrentada pela turma ao se deparar com a desnaturalização dos modos de fazer desenho. Os tensionamentos produzidos entre incomodar e acomodar o corpo surpreendem a cada instante quando os arranjos corporais préestabelecidos são provocados. Se a escola, tradicionalmente, busca uniformizar os corpos garantindo uma performatividade especificamente enquadrada, propomos uma aula de artes na contramão desse fluxo, escavando uma investigação que reverbera em outros modos de habitar o ambiente escolar. Quando convidamos o corpo a se perceber e a inaugurar movimentos na relação com o que o afeta, a aula passa a ser compreendida como processo relacional que nos aciona a um estado de presença e nos possibilita abrir espaço para um campo de afetações: há efeito no afeto.

Ao experimentarmos com as turmas caminhos do desenho através do corpo, o sentido de corpo se desloca de uma ideia fixa basicamente formulada sobre "o que eu acho que é corpo" para tornar-se uma questão: eu me percebo corpo? 


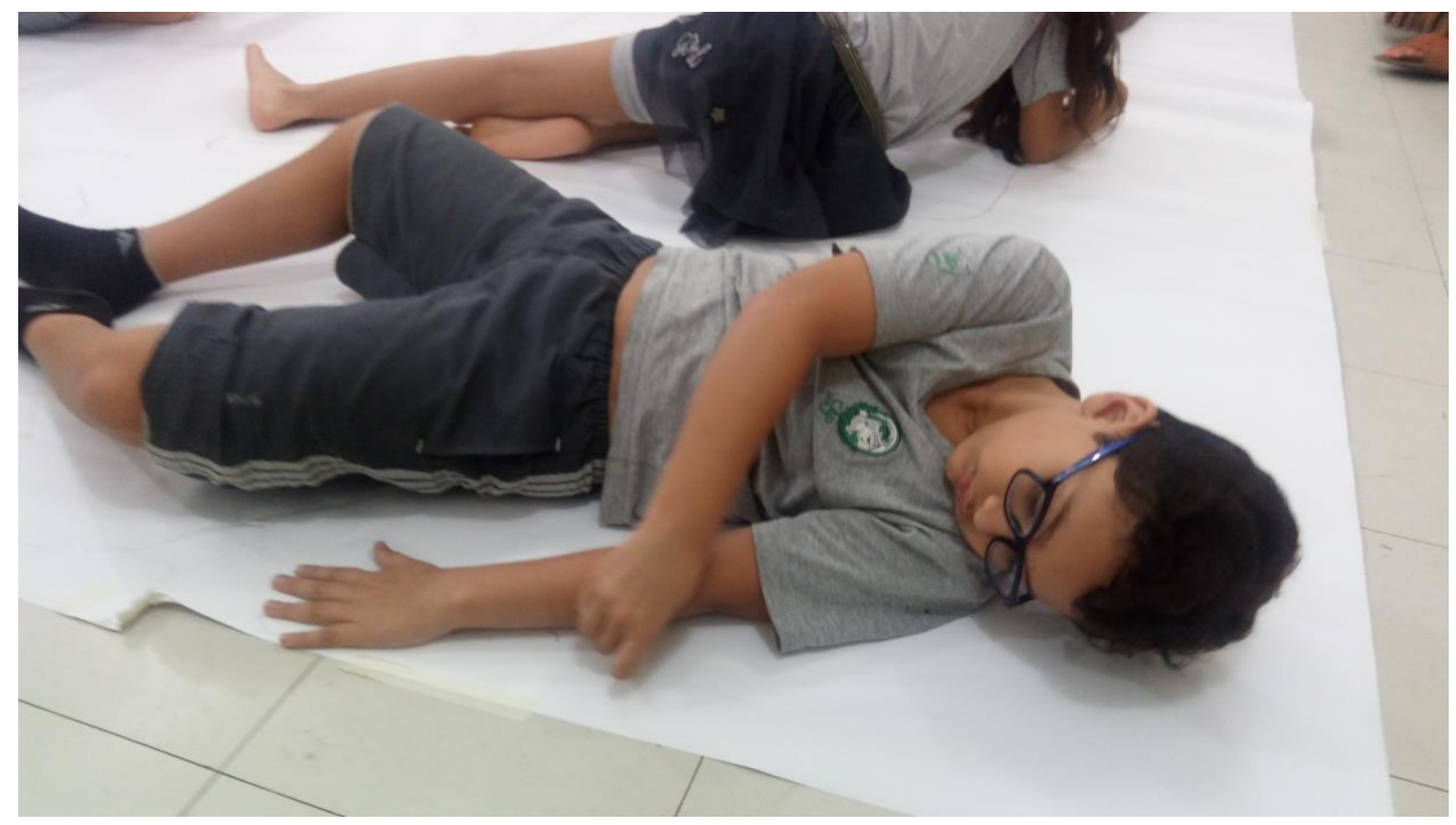

Imagem 6 - Registro de aula. Cap-UFRJ, 2019.

\section{Como aponta Eugênio Paccelli Horta:}

É como se a percepção do próprio corpo, a partir de uma movimentação lúdica, o liberasse de uma gesticulação social, de qualquer espécie de acordo ou préconceitos que se apresentam quando um grupo se reúne em uma sala de aula. Alunos corporalmente sensíveis - antes de executar qualquer gesto direcionado ao traço - para qual seria a origem de sua própria mobilidade. Alunos que pensam não só a linha, o desenho; mas em sua origem, o pensamento, que se realiza no lugar sobre si mesmo - o corpo. (HORTA, 2010, p.8)

Alteridade. Perceber-se no outro e notar aquilo que me difere, logo me constitui enquanto subjetividade. Perceber pelo crivo da corporeidade que eu caibo na minha colega de turma, mesmo com todas as nossas diferenças e que elas cabem em mim também. Perceber com o corpo aquilo que vivo. Perceber no corpo as semelhanças e diferenças. Situar-se no corpo enquanto lugar de onde vemos o mundo, percebendo-se corpo e mundo. Isso implica perceber a si próprio em criação contínua, realizando uma travessia da forma fixada, formadora da instituição disciplinar, para a forma subjetiva, permeável, tramada de afetações, constantemente em (per)formação:

Considerar o corpo em movimento como um sistema autopoiético é reconhecê-lo como fenômeno que não se reduz à causalidade linear; é considerar ainda que o ser humano não seja um ser determinado, mas uma criação contínua. É, por fim, uma tentativa de abordar a corporeidade não 
como algo abstrato, é recusar as dicotomias, é ensaiar atitudes complexas para compreender o humano e sua condição de ser corpóreo em incessante movimento. (NÓBREGA, 2008, p. 145)

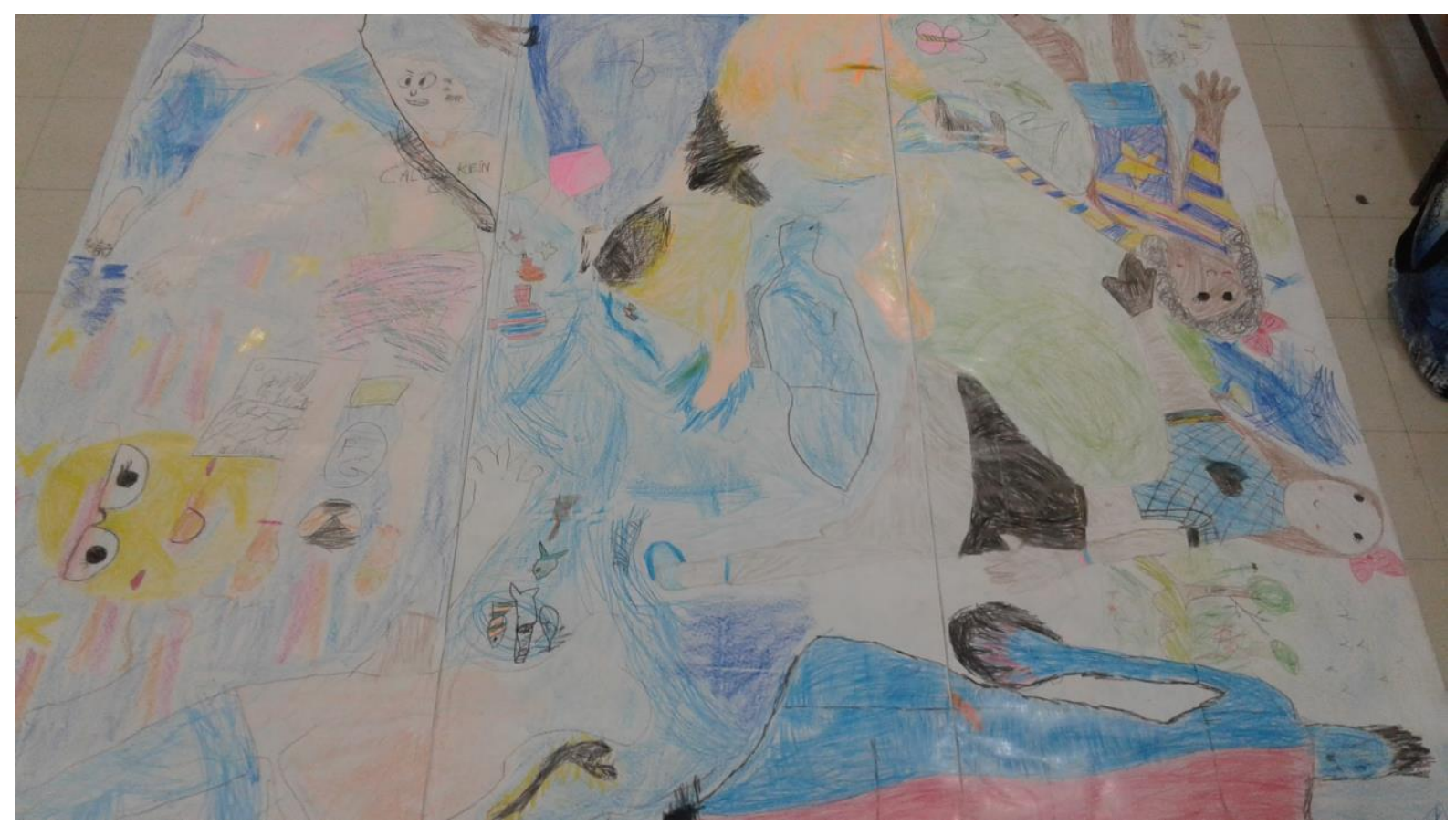

Imagem 7 - Registro de aula. Cap-UFRJ, 2019.

Desse modo, tecemos caminhos para a elaboração de metodologias contemporâneas no ensino de artes visuais, as quais busquem dar conta das anunciações corporais da contemporaneidade. Enquanto mulheres, artistas-educadoras e pesquisadoras, nos perguntamos: se não cabemos em um mesmo corpo, que corpos estamos desenhando com nossos estados de presença no cotidiano escolar? Bell Hooks em Eros, erotismo e processos pedagógicos nos leva a pensar sobre a presença do desejo na sala de aula como elemento mobilizador dos processos de ensino e de aprendizagem. Reforça a necessidade de estarmos inteiras, de coração inteiro, na sala de aula e não como espíritos descorporificados (2018, p. 147), apontando como um dos pontos centrais da pedagogia crítica feminista "a insistência em não reforçar a divisão corpo/mente":

A compreensão de que eros é uma força que intensifica nosso esforço global de autorrealização, de que ele pode fornecer uma base epistemológica que nos permita explicar como conhecemos aquilo que conhecemos, possibilita tanto professores quanto estudantes a usar tal energia no contexto da sala de aula de forma a revigorar a discussão e a estimular a imaginação crítica (HOOKS, 2018, p. 150). 
Entre os títulos "Engenhoca humana", "Corporal", "Como é o ser humano" pensados pelas crianças para o desenho produzido coletiva e colaborativamente, ficamos com "Nós", palavra-articulação, ponto de chegada ou de partida do nosso jeito de desenhar o mundo de corpo inteiro e de forma compartilhada.

\section{REFERÊECIAS}

HOOKS, Bell. Eros, Erotismo e Processos Pedagógicos. In: LOURO, Guacira Lopes (org). O corpo educado - Pedagogias da sexualidade. São Paulo: Autêntica, 2018. p. 145-156

HOOKS, Bell. A construção de uma comunidade pedagógica. In: Ensinando a transgredir A educação como prática da liberdade.São Paulo: Martins Fontes, 2019. p. 173-222

HORTA, Eugênio Paccelli da Silva. Desenho inscrito no corpo. Tese (Doutorado). Escola de Belas Artes. Universidade Federal de Minas Gerais. Minas Gerais, 2010.

MERLAU-PONTY, Maurice. Fenomenologia da Percepção. São Paulo. Martins Fontes, 1999.

NÓBREGA, Terezinha Petrucia. Corpo, percepção e conhecimento em Merleau-Ponty. Estudos de Psicologia. Universidade Federal do Rio Grande do Norte, 2008. p. 141-148.

\footnotetext{
i Virna Bemvenuto é artista-educadora graduanda em Educação Artística - Artes Plásticas na Escola de Belas Artes da UFRJ, atua como pesquisadora bolsista PIBIAC no projeto O Corpo nas Artes Visuais no CAp-UFRJ. Atua como performer investigando o corpo como matéria expressiva e suas relações. Email: virnabemvenuto@gmail.com. Cidade: Rio de Janeiro. País: Brasil. ORCID: http://orcid.org/0000-0003-32557658 . Filiação: Universidade Federal do Rio de Janeiro.

ii Letícia Carvalho é artista-educadora no Colégio de Aplicação-UFRJ e mestra em Estudos Contemporâneos das Artes pela UFF. Desenvolve pesquisa relacionada aO Corpo nas Artes Visuais, onde atua como coordenadora, pesquisadora e performer. Email:cabelenta@gmail.com. Cidade: Rio de Janeiro. País: Brasil. ORCID: https://orcid.org/0000-0003-0344-286X. Filiação: Universidade Federal do Rio de Janeiro.
} 